\title{
Coordenador pedagógico: possibilidades e limites da formação continuada
}

\author{
Pedagogical coordinator: possibilities and limits of continuing \\ education
}

\begin{abstract}
Simone Regina Manosso Cartaxo Doutora em Educação pela Pontifícia Universidade Católica do Paraná - PUCPR. Professora da Universidade Estadual de Ponta Grossa - UEPG. Ponta Grossa/PR. Brasil. simonemcartaxo@hotmail.com
\end{abstract}

\author{
Victoria Mottim Gaio \\ Doutoranda em Educação pela UEPG. \\ Professora da Rede Municipal de Ensino de Ponta Grossa. \\ vic_mottim@hotmail.com
}

\begin{abstract}
Resumo: O objeto deste estudo é a formação continuada do coordenador pedagógico de uma Rede Municipal de Ensino. O problema de investigação indaga: quais as possibilidades e os limites da formação continuada para a realização do trabalho do coordenador pedagógico nas escolas municipais? A pesquisa de cunho qualitativo pautouse na análise de conteúdo, com base em Bardin (2010), de documentos legais do município e da realização de entrevistas semiestruturadas com 10 coordenadores pedagógicos. A concepção de formação continuada fundamentase no eixo epistemológico da teoria de Martins (1996) como expressão da prática. Os resultados indicam: a) possibilidades: formação para o iniciante na função; definição do papel de formador dos professores; troca de experiências; b) limites: formação distanciada das necessidades da escola e do protagonismo docente; definição da função do coordenador pedagógico alinhada aos moldes da sociedade capitalista.
\end{abstract}

Palavras-chave: Coordenador pedagógico. Formação continuada. Teoria e prática.

Abstract: The object of this study is the continuing education of the pedagogical coordinator of a Municipal Education Network. The research problem asks: What are the possibilities and limits of continuing education for the work of the pedagogical coordinator in municipal schools? The qualitative research was based on the content analysis, based on Bardin (2010), of legal documents of the municipality and semi-structured interviews with 10 pedagogical coordinators. The conception of continuing education is based on the epistemological axis of Martins's (1996) theory as an expression of practice. The results indicate: a) possibilities: training for the beginner in the job; definition of the role of teacher trainer; exchange of experiences; b) limits: formations distanced from the needs of the school and the teaching role; definition of the role of the pedagogical coordinator in line with the molds of the capitalist society.

Keywords: Pedagogical coordinator. Continuing education. Theory and practice. 


\section{Introdução}

A reestruturação do papel social da escola a partir da década de 1980 exigiu um redimensionamento do "[...] compromisso político-pedagógico com a qualidade do ensino na perspectiva de contribuir com uma sociedade mais justa e igualitária" (ALMEIDA; SOARES, 2010, p. 39). Nesse sentido, a formação do pedagogo é repensada como parte da reformulação da escola como um todo para atuar no ensino, na organização do trabalho pedagógico, na gestão e em outras áreas afins à educação (SCHEIBE; AGUIAR, 1999; ANFOPE, 1998).

A complexidade do trabalho do pedagogo ${ }^{1}$ na escola é marcada pelas diferentes atribuições (PLACCO; SOUZA; ALMEIDA, 2012; PLACCO, 2012) e pelos determinantes internos e externos à sua função. Não obstante, essa complexidade, ainda que em um espaço contraditório, da função do coordenador pedagógico pode contribuir significativamente para a escola ao trabalhar na construção da sua identidade (DOMINGUES, 2009), no Projeto Político Pedagógico, na elaboração de projetos para a formação dos professores e na articulação com a comunidade escolar.

$\mathrm{Na}$ complexidade das funções do coordenador pedagógico, reconhecemos desafios, possibilidades e limites e consideramos que, concomitante ao seu trabalho na escola, a proposta de sua formação continuada "[...] deve conjugar ações no sentido de lhe dar respaldo teórico e prático para que possa conseguir mudanças didático-pedagógicas qualitativas no âmbito das escolas" (BRECKENFELD; GUIRAUD; ROMANOWSKI, 2009, p. 3621). Assim sendo, delineamos como objetivo deste estudo analisar as possibilidades e os limites da formação continuada do coordenador pedagógico a partir do desvelamento de como vem se constituindo a sua formação na Rede Municipal de Ensino (RME) de Ponta Grossa no período entre 1989 a 2018.

Concebemos a formação continuada pautada na prática social do sujeito e assumimos o eixo epistemológico da teoria como expressão da prática. A teoria como expressão da prática (MARTINS, 1996) considera que a prática do sujeito, situada historicamente, é a base do conhecimento, ou seja, a partir da prática e das formas de agir é que as formas de pensar serão sistematizadas. A teoria não é o ponto de partida e não é guia da prática, ela será um auxílio para compressão da totalidade e para buscar a transformação da prática. Desse modo, o ponto de partida é a própria prática pedagógica produzida na escola onde os sujeitos atuam.

Para a realização do estudo e para a escolha dos encaminhamentos metodológicos, optamos pela pesquisa de cunho qualitativo, entendida como aquela que busca a compreensão dos fenômenos e uma explicação dos fatos (SÁNCHEZ GAMBOA, 2007). Este estudo foi, 
dessa maneira, desenvolvido com a análise de documentos, que situam historicamente o coordenador pedagógico na RME de Ponta Grossa, e com a realização de entrevista semiestruturada com coordenadores pedagógicos das escolas.

Os documentos sobre a formação continuada realizada no município e a legislação que regulamenta a atuação do coordenador pedagógico ${ }^{1}$ foram localizados no arquivo da própria Secretaria Municipal de Educação (SME), na Casa da Memóriaª ${ }^{2}$ no site de Leis Municipais e na Prefeitura Municipal de Ponta Grossa, além de documentos pessoais dos sujeitos entrevistados.

As entrevistas realizadas com dez coordenadores, conforme indica o Quadro 1, foram gravadas e transcritas, para posterior análise de conteúdo (BARDIN, 2010).

Quadro 1 - Coordenador Pedagógico

\begin{tabular}{|c|c|}
\hline Coordenador Pedagógico & Período de atuação e função \\
\hline CP1 & $\begin{array}{l}1996 \text { até } 2000 \text { - Orientador } \\
2001 \text { até } 2004 \text { - Coordenador Pedagógico }\end{array}$ \\
\hline $\mathrm{CP} 2$ & $\begin{array}{l}1997 \text { até } 2000 \text { - Supervisor } \\
2006 \text { até } 2011 \text { - Coordenador Pedagógico }\end{array}$ \\
\hline CP3 & $\begin{array}{l}1998 \text { até } 2000 \text { - Supervisor } \\
2014 \text { até os dias atuais - Coordenador Pedagógico }\end{array}$ \\
\hline $\mathrm{CP} 4$ & 2001 até 2013 - Coordenador Pedagógico \\
\hline CP5 & 2003 até os dias atuais - Coordenador Pedagógico \\
\hline CP6 & 2005 até 2015 - Coordenador Pedagógico \\
\hline CP7 & 2008 até os dias atuais - Coordenador Pedagógico \\
\hline CP8 & 2013 até os dias atuais - Coordenador Pedagógico \\
\hline CP9 & 2014 até os dias atuais - Coordenador Pedagógico \\
\hline CP10 & 2017 até os dias atuais - Coordenador Pedagógico \\
\hline
\end{tabular}

Fonte: As autoras (2018).

Legenda: CP - Coordenador Pedagógico.

A realização desta pesquisa contemplou entrevistas com outros profissionais da educação do município que auxiliaram na construção do histórico da Secretaria de Educação e na contextualização da temática em questão. No entanto, para este texto, foi realizado um recorte com os dados dos coordenadores que contribuíram para destacar os principais pontos da sua formação.

\footnotetext{
1 A opção por "coordenador pedagógico", neste texto, deu-se em função do contexto analisado e corresponde, em outros contextos, ao pedagogo.

${ }^{2}$ A função de coordenação pedagógica é ocupada por professores com experiência de sala de aula que são convidados pela SME de acordo com seu desempenho. O profissional recebe gratificação de 15 por cento do vencimento inicial da carreira.
} 
Considerando a complexidade do trabalho do coordenador pedagógico e a defesa da formação continuada pautada na prática dos sujeitos, divulgamos os resultados desta pesquisa realizada sobre o coordenador pedagógico a seguir.

\section{Formação continuada para o coordenador pedagógico}

Nesta seção, trazemos uma síntese da análise sobre os momentos e os movimentos da formação continuada do coordenador pedagógico na RME de Ponta Grossa; os principais pontos destacados pelos coordenadores pedagógicos sobre a formação continuada; e uma análise das possibilidades e dos limites da formação continuada do coordenador pedagógico.

\subsection{Momentos e movimentos da formação continuada do coordenador pedagógico}

A análise de documentos e das entrevistas indicou a existência de momentos e de movimentos na formação continuada a partir de 1989, quando os supervisores e os orientadores educacionais foram inseridos nas escolas do município. Partimos da informação de que a função de coordenador pedagógico na SME de Ponta Grossa é recente e que era ocupada pelo supervisor e orientador escolar, o que nos mobilizou a olhar para o contexto nacional e local, a fim de localizarmos e descrevermos o percurso do coordenador pedagógico na RME.

A função do supervisor e do orientador era dividida, com tarefas fragmentadas, de acordo com o viés tecnicista da década de 1970. Além disso, a formação desses profissionais ocorria no curso de Pedagogia que formava os professores para o Magistério, diretores de escolas, orientadores educacionais, supervisores escolares e inspetores de ensino (SAVIANI, 2009).

Muitos questionamentos sobre a fragmentação da formação do supervisor e do orientador ocorreram pela compreensão de que a atividade socialmente requerida seria apenas uma, a educação, e o profissional apto a desempenhá-la seria, igualmente, apenas um, o pedagogo (SAVIANI, 2008).

A contextualização levou-nos a identificar diferentes momentos, levando em conta os estudos de Martins (2006). Essa contextualização histórica permitiu compreender as mudanças que envolvem a atuação do pedagogo e entender o movimento da sua formação continuada. $\mathrm{O}$ primeiro momento (1989 a 2000) ficou marcado pela inserção do supervisor e do orientador nas escolas municipais e pela formação continuada com destaque para as práticas. Esse movimento 
local, no município de Ponta Grossa, está relacionado ao movimento nacional de organização do trabalho na escola e da produção e da sistematização coletiva do conhecimento (MARTINS, 2006).

A formação continuada, nesse período, voltou-se para a valorização das necessidades da prática, com dias específicos de estudo e de formação na própria escola, com a proposição de eventos e de publicações coletivas que tiveram como base as experiências vivenciadas pelos supervisores e orientadores na organização dos trabalhos e da formação dos docentes. Destacamos, nesse contexto, um movimento de superação da fragmentação do trabalho e do viés fiscalizador dos supervisores e dos orientadores.

O segundo momento (a partir de 2001) caracterizou-se pela unificação do trabalho do pedagogo, denominado coordenador pedagógico, e a mudança no viés da formação continuada em parceria com a iniciativa privada. Nesse período, a formação continuada do coordenador pedagógico foi realizada pelo Instituto Ayrton Senna e pela equipe da Secretaria de Educação, com o programa Escola Campeã, com temas relacionados ao gerenciamento da escola eficaz, rotinas financeiras, rotina do dia a dia. Em julho de 2016, uma nova parceria com a iniciativa privada foi realizada com a Fundação Lemann.

Essas parcerias têm sido alvo de estudos entre diferentes autores como Adrião e Peroni (2011) e D'Avila (2013) que analisam os impactos e as implicações da iniciativa privada na educação, principalmente ao tratar da formação continuada, voltada à formação de líderes para atingir os objetivos alinhados muito mais a uma sociedade capitalista do que a uma formação emancipadora dos sujeitos.

A partir do reconhecimento do movimento que vem se constituindo sobre a formação continuada do coordenador pedagógico na RME de Ponta Grossa, apresentamos, a seguir, os principais pontos que emergiram das entrevistas com os coordenadores.

\subsection{O que dizem os coordenadores das escolas sobre a formação continuada}

A análise de conteúdo das entrevistas considerou critérios de classificação significativos e coerentes com o objetivo proposto na pesquisa. Nesse sentido, a categorização dos dados, a qual, segundo Bardin (2010), consiste no agrupamento de dados que possuem aproximações em suas características, para esta análise, utilizamos do critério semântico, resultando em categorias temáticas. São elas: a) formação para o coordenador pedagógico iniciante na função; b) formação como espaço para troca de experiências; c) formação para a definição do papel do coordenador 
pedagógico; d) formação para atuar como formador no interior da escola; e) formação para a realização do planejamento de aula; f) formação para resultados; g) formação e necessidades da escola.

a) Formação para o coordenador pedagógico iniciante na função

O início de uma função é sempre um desafio, mesmo que o coordenador pedagógico tenha experiência de sala de aula, ele vivencia novas situações provocadoras (VAILLANT; MARCELO, 2012). Segundo os dados, os coordenadores indicaram diferentes momentos nos quais a SME ofereceu uma formação para os que estavam iniciando a função nas escolas.

\footnotetext{
Naquele período, eu tive muita orientação. Tinha uma equipe muito eficiente, elas nos chamavam para explicar determinadas coisas que, na verdade, a gente pensa que são detalhes [...]. (CP4) (O relato refere-se ao ano de 2002).

Eu entrei em abril de 2008 e já fui para uma formação, antes de eu começar a atuar mesmo, eu já tive três dias de formação. [...]. Tive uma reunião, uma formação de todo aspecto técnico, da função do coordenador pedagógico [...]. (CP7) (O relato refere-se ao período de 2008).
}

Alguns coordenadores mencionaram as dificuldades iniciais da função e destacaram a relevância de uma formação específica para eles. Outros coordenadores indicaram a ausência de formação para quem estava iniciando bem como as dificuldades vivenciadas.

\footnotetext{
No primeiro ano, o que eu esperava era que alguém me dissesse quais eram as funções do pedagogo na prática na Rede Municipal de Ponta Grossa, que o curso de graduação não dá conta. Infelizmente, nós não tivemos isso, eu fui em busca muito de uma forma mais autônoma, mais solitária. (CP1) (O relato refere-se ao ano de 1996).

Quando eu iniciei, não foi oferecido nada, a minha experiência era a experiência das pedagogas que trabalharam comigo quando eu estava na gestão, na direção. (CP6) (O relato refere-se ao ano de 2005).

No início. foi difícil, porque eu só trazia a minha experiência de sala de aula de professora [...]; a gente não teve uma formação específica [...]. (CP9) (O relato refere-se ao ano de 2014).
}

Embora não tenha sido uma constante, a formação para os iniciantes na função da coordenação pedagógica foi destacada como importante para compreender e enfrentar os desafios iniciais. Essa é uma realidade do contexto nacional revelada pelas pesquisas sobre a inserção profissional docente que apontam fragilidades das Secretarias de Educação para desenvolver programas de formação que atendam aos profissionais (ROMANOWSKI et al., 2016). A fragilidade de programas de inserção profissional mobiliza os profissionais a buscarem, entre seus pares, formas de organização do trabalho. 
A troca de experiências é vista como um fator positivo na formação continuada, pois possibilita o compartilhamento dos desafios enfrentados pelos profissionais e a busca coletiva de estratégias de atuação. A formação voltada à troca de experiências destacou-se em diferentes momentos.

Foram boas as formações, mais no sentido de troca de experiências com os outros profissionais mais antigos. (CP1) (O relato refere-se ao período de 1996-2004).

Como nós trabalhávamos muito com troca de experiência, nós trocávamos, enquanto equipe de supervisora, várias experiências. O que em uma escola dava certo, a gente tentava fazer na da gente. O que na minha deu certo, eu relatava [...]. (CP2) (O relato refere-se ao período de 1997-2000).

A gente trocava bastante ideia com as outras pedagogas que estavam na reunião. Troca de experiência, contribuía sim! (CP6) (O relato refere-se ao período de 2005-2015).

A gente fez um grupo de estudo, tinha durante todo o ano, em que a gente tinha essa troca de experiência, estudava o texto e depois a gente partilhava. (CP9) (O relato refere-se ao ano de 2014).

A valorização dos momentos de trabalho coletivo e a troca de experiências entre os coordenadores pedagógicos merecem destaque uma vez que as relações estabelecidas na escola e na sociedade, de forma geral, têm levado muito mais a ações individuais e competitivas. A busca de reformulação da escola e de seu papel social comprometido com os interesses da maioria da população requer propostas comprometidas à participação de todos.

Autores como Imbernón (2011) reforçam a importância da troca de experiência na formação continuada, um trabalho conjunto entre os profissionais. Podemos ressaltar esse fator como um caminho para a sistematização e a produção coletiva do conhecimento, pois, juntos, os coordenadores podem conversar, questionar, debater, estudar, para produzir seu conhecimento de forma coletiva. Nesse âmbito, considera-se a prática do sujeito, sendo uma possibilidade para se pensar a formação no eixo epistemológico da teoria como expressão da prática (MARTINS, 1996).

\section{c) Formação para a definição do papel do coordenador pedagógico}

A função do coordenador pedagógico foi se constituindo historicamente, passando das habilitações de supervisão e de orientação para o pedagogo unificado e, nesse percurso, ficaram muitas dúvidas sobre o seu papel e suas atribuições na escola. 
Os coordenadores relataram que as formações têm auxiliado para a definição do trabalho na escola.

\begin{abstract}
$\mathrm{Na}$ época, nós trabalhávamos com temas relacionados à supervisão escolar, todo material era da supervisão, a avaliação, o planejamento; era batido bastante na questão do planejamento do professor, de planejamento coletivo, como trabalhar com professor. (CP2) (O relato refere-se ao período de 1997-2000).
\end{abstract}

Era colocado mais sobre a gestão democrática, a função do pedagogo, que, na verdade, a gente faz muito mais na coordenação pedagógica do que só o nosso trabalho. Você acaba fazendo de tudo na escola e isso dificulta um pouco. (CP6) (O relato refere-se ao período de 2005).

Os temas são mais ligados à gestão pedagógica, à gestão de sala de aula, às dificuldades. Último texto que eles mandaram é de gestão de sala de aula, dificuldades de aprendizagem, como lidar com isso. (CP8) (O relato refere-se ao período de 2017).

Agora sim está bem definido o papel do coordenador, porque, antes, o coordenador era aquele que apagava incêndio na escola. [...] sistematizou o papel do coordenador [...], definiu bastante, até o horário, o cronograma, como que você vai se organizar durante a semana. Como se tivesse desorganizado, e eles organizaram o nosso trabalho. (CP9) (O relato refere-se ao ano de 2016).

Os relatos dos coordenadores indicam um movimento para a definição do seu papel e ressaltam seu aspecto positivo. No entanto, identificamos que esse movimento é determinado pelo contexto e atende a diferentes interesses, como o caso do $\mathrm{CP} 9$, ao destacar uma forma de organização bastante técnica; e do CP2, que aponta para uma ação mais coletiva.

Ressaltamos a importância do papel do coordenador como formador para os professores, como aborda Geglio (2012), o qual destaca a formação para discutir problemas pedagógicos, questões referentes à sala de aula, aos conteúdos de ensino, aos alunos, entre outros.

Placco (2002) valoriza o trabalho do CP como formador, sendo um momento para auxiliar os docentes no desenvolvimento de suas práticas, e, nesse movimento de formação, tanto professor como coordenador se formam e se transformam. Da mesma forma, Pinto (2011) destaca essa função e afirma que a formação proposta pelo coordenador visa o aprimoramento profissional dos docentes, de modo a promover o processo de reflexão nos docentes quando participa das suas aulas, inserindo-se em sala de aula, podendo problematizar situações. No âmbito desse auxílio direto do coordenador ao professor, o próximo item apresenta uma possibilidade ao coordenador pedagógico.

\title{
d) Formação para atuar como formador no interior da escola
}

O processo de formação continuada no interior da escola é uma das atribuições do coordenador pedagógico e articula-se à compreensão da natureza do trabalho docente e do 
ensino. Os coordenadores indicaram iniciativas de formações ofertadas pela SME para atender a essa necessidade como formadores:

Matemática, português, eu lembro muito que veio a Sandra Bozza, mais do que uma vez, para apresentar sugestões de trabalhos voltados à questão de alfabetização, tinha o pessoal das próprias áreas da Secretaria Municipal de Educação[...]. (CP4) (O relato refere-se ao ano de 2002).

Sempre era trabalhada a questão do português, da matemática, os conteúdos básicos, a questão das diretrizes que agora que está bem especificado em livros, foi feito até o livrinho da secretaria, tudo certinho para facilitar com as matrizes, para facilitar o trabalho. (CP5) (O relato refere-se ao período de 2003-atual).

A gente pode chegar e colocar para todos os professores: "olha, gente, planejamento precisa ser assim, não sou eu, pedagoga, que estou falando, é a formação". Então, eu tenho a minha formação, mas eu também posso dar essa formação para os professores, isso que é bacana do instituto. (CP9) (O relato refere-se ao ano de 2017).

Formações muito voltadas para as áreas específicas do conhecimento, na área de língua portuguesa, na área de matemática, na área de ciências, história, geografia. Mais na área de língua portuguesa e matemática que a gente teve essas formações. (CP7) (O relato refere-se ao período de 2013).

Nós tivemos formação de português, de matemática para os professores, que eu acredito que a fundação também está envolvida, então foi muito rico. (CP9) (O relato refere-se ao período de 2017).

A formação centrada nas áreas do conhecimento é recorrente na fala dos coordenadores e expressa a necessidade de pensar o planejamento e o encaminhamento metodológico de cada objeto de ensino. Eles destacam que os processos formativos auxiliam na retomada com os professores na escola.

\section{e) Formação para a realização do planejamento de aula}

O planejamento das aulas é essencial para atingir os objetivos de ensino, e, como formador, o coordenador pedagógico auxilia os docentes na sua elaboração e no seu desenvolvimento. Para realizar esse trabalho, a formação continuada foi vista como fundamental para dar suporte e embasamento na orientação aos professores.

Para você chegar para o professor e dizer assim: "Olha, professor, o teu planejamento não está legal, você podia mudar assim”, é diferente. A gente tem uma pauta, como eles dizem, como veio, a pauta formativa de como elaborar um planejamento. Então, a gente pode chegar e colocar para todos os professores: "Olha, gente, planejamento ele precisa ser assim, não sou eu, pedagoga, que estou falando, é a formação”. (CP9) (O relato refere-se ao período de 2017).

A rede não tinha esse hábito de planejar, fazer todo um planejamento de aula de tudo; então, esse ano eles estão introduzindo. Até você trabalhar na cabeça dessas professoras o quanto é importante organizar esse trabalho... Você precisa planejar porque você tem que atender aquela criança, o bom aluno, o aluno médio, o aluno fraco, todos são teus, não existe mais aquela homogeneidade, porque as pessoas aprendem de formas diferentes. (CP10) (O relato refere-se ao período de 2017). 
Recentemente, o direcionamento do planejamento pela Secretaria de Educação tem auxiliado, segundo depoimento dos coordenadores, no trabalho com os professores, fato que não ocorria em outros períodos. Os coordenadores dizem que conseguem realizar o trabalho com as professoras, pois tornou-se uma exigência na RME.

\section{f) Formação para resultados}

Os coordenadores destacaram que participam de formações sobre as avaliações em larga escala. Essas avaliações são realizadas no território nacional e são comunicadas em índices de aproveitamento das escolas. Os municípios, de forma geral, têm se organizado para realizar um trabalho de acompanhamento junto às escolas para atingir melhores resultados.

Nós tínhamos uma formação que era assim, todos os sentidos voltados para resultados. Então, como é que você planeja para atingir resultados? Nós tínhamos sempre a impressão de que nós estávamos em uma formação empresarial, não tinha cunho educativo, o aluno não era tratado ali, era tratado o resultado desse aluno. (CP1) (O relato refere-se ao período de 2001-2004).

A meu ver, eram mais políticas, questões de números, nós temos que atingir tal índice atrás de tal situação, tinham aquelas fichas do instituto Ayrton Senna, aquilo era muito complicado, porque, às vezes, a gente se prendia demais em números. (CP4) (O relato refere-se ao período de 2001-2013).

Prova Brasil esse ano, então foi feito um trabalho muito sério em cima, sabe? Foi excelente o trabalho da Secretaria, então a gente recebeu treinamento, vinha para a escola treinar as professoras. A gente tinha que repassar, você entra na plataforma, baixa os vídeos, videoaula, a gente usou muito videoaula esse ano pra vencer todos os descritores, todos os conteúdos, sabe? (CP10) (O relato refere-se ao período de 2017).

Os relatos indicam que os objetivos da formação para resultados têm sido uma constante na RME, e a ação do coordenador pedagógico na organização do trabalho na escola é direcionado e monitorado para alcançar melhores resultados nas avaliações em larga escala.

\section{g) Formação e necessidades da escola}

Autores como Imbernón (2011) e Nóvoa (1995) destacam a importância da formação que considere as questões da prática, que leve os profissionais a pensar e a refletir, em busca de soluções para problemas e para transformá-la.

Os coordenadores possuem expectativas de que a formação continuada os ajudem quanto às necessidades das suas práticas. Ressaltam isso ao afirmar que a troca de experiência e os grupos de estudos são realmente importantes para trabalhar as reais necessidades da escola. Como afirma o CP2: 
Uma troca de ideia mesmo. É muito válido para a formação, nós tivemos agora o ano passado uma formação parecida na Secretaria de Educação, ir visitar as escolas e as escolas nos mostravam o que estava acontecendo, como ela fazia tal coisa. Eu peguei muitas ideias dessas visitas que nós fizemos, dos relatos das diretoras, então, a gente aprende muito mais assim do que com muita teoria, teoria, que não vai te ajudar em muita coisa. Teoria ajuda, é claro, mas não tanto quando uma troca de experiência. (CP2) (O relato refere-se ao período de 2017).

No entanto, eles afirmam que, por vezes, as formações acontecem com estudos de textos que não condizem com as suas necessidades, que não auxiliam em questões da prática e do cotidiano escolar. Comentam sobre formações burocráticas e com apresentação de temas selecionados pela equipe formadora que, por vezes, alinhavam-se mais às necessidades de demarcação de espaço da Secretaria do que das necessidades da escola:

A gente era chamada para ter orientação, trabalhava de acordo com temas que vinham ao encontro das necessidades da rede como um todo, mas nem sempre essa formação atendia às necessidades da gente especificamente. Às vezes eu sinto que havia temas que eram meio utópicos, que iam às vezes ao encontro mais das necessidades políticas do que realmente necessidades da rede em si, da prática do dia a dia. (CP4) (O relato refere-se ao período de 2001-2013).

Em relação ao cotidiano da escola, isso é fragmentado, porque não te ajuda a organizar o trabalho. O coordenador parece que não tem autonomia para pensar o espaço, para pensar aquilo que ele está fazendo. São sempre formações importadas. (CP3) (O relato refere-se ao período de 2013-2017).

Que venha ao encontro da realidade e das necessidades da escola, que eles ouçam mais a escola. Às vezes, o que é para um não é para outro, então tem que partir da escola, partir daqui! Eles têm que ouvir o que a escola está precisando! É igual ao que a gente faz com as professoras: a gente vê o que que é a necessidade para a gente trabalhar, e deles teria que ser a mesma coisa. Então, ouvir mais as escolas, o que que a gente precisa, e tentar ajudar nesse sentido, na real necessidade da escola mesmo. (CP5) (O relato refere-se ao período de atual).

Os coordenadores valorizam a formação continuada; no entanto, eles chamam atenção para o reconhecimento das necessidades que estão vivenciando no momento nas escolas, que o ponto de partida seja a própria prática pedagógica produzida na escola que atuam. Requerem também espaço para que "as escolas" sejam ouvidas e possam ter autoria no desenho de seu processo formativo.

A formação continuada seria um dos espaços a proporcionar esse momento de pensar a prática, de questioná-la, de buscar fundamentos para negá-la e, assim, pensar, refletir e buscar a transformação. Isso se efetiva quando a concepção de formação reconhece os sujeitos trabalhadores e busca realmente auxiliar nas necessidades da prática, de acordo com a formação da teoria como expressão da prática (MARTINS, 1996), mas o que tem sido priorizado não são 
essas questões, pois a formação está voltada ao fazer e à execução, sendo pensada por outros para a escola e não com a escola.

Os pontos destacados pelos coordenadores sobre a formação continuada desencadearam uma análise das possibilidades e limites dessa formação. Essa análise é apresentada a seguir.

\section{Formação continuada para o coordenador pedagógico: entre possibilidades e limites}

A partir da formação continuada oferecida aos coordenadores pedagógicos, identificamos possibilidades e limites para a realização do trabalho pedagógico comprometido com os interesses de uma sociedade mais democrática. Encontramos como possibilidades a formação para o coordenador pedagógico iniciante na função, subsídios para seu trabalho como formador dos professores e a definição do seu papel como coordenador pedagógico. Ao mesmo tempo que identificamos as possibilidades, alguns limites emergiram das análises.

Os limites foram definidos a partir de pressupostos teóricos que orientam a função do coordenador na construção da identidade da escola por meio do Projeto Político Pedagógico e da formação continuada pautada na prática social dos sujeitos. Nesse contexto, foram identificamos como limites:

- Ausência de programas permanentes de inserção profissional para os iniciantes na função.

- Pouco espaço de estudo e trocas de experiências na perspectiva da autonomia e do trabalho coletivo.

- Definição restrita do papel do coordenador pedagógico para atender às demandas do capital. Essa perspectiva caminha na contramão dos princípios para a construção de uma educação emancipatória e humanizadora.

- Dependência das instruções da SME para organizar o trabalho pedagógico com e na escola.

- Delimitação de ações técnicas a fim de supervisionar a ação do professor e dos resultados da aprendizagem fundamentado na racionalidade técnica.

- Foco na avaliação centrada nos resultados com implicações para o planejamento (a seleção e a reorganização dos conteúdos com vistas à realização das provas têm levado a reducionismos e a práticas de treinamento para obter melhores resultados nos índices de avaliação). 
Ao elencarmos os limites da formação continuada, destacamos que, nas entrevistas, identificamos que o coordenador pedagógico aderiu à ideia de que a formação continuada tem auxiliado na compreensão e na definição do seu papel na escola. No entanto, analisamos que essa visão está baseada na concepção do coordenador tarefeiro, com função unificada, associada aos moldes da sociedade capitalista, como apresentado por Kuenzer (2002), que explica não ser suficiente a unificação no âmbito da formação, pois é preciso que esta se dê a partir das categorias que historicamente tem se construído no campo da pedagogia emancipatória.

Conforme aponta Peroni (2013), há influência do setor privado nas redes públicas de ensino e consequências dessa relação no trabalho dos profissionais da escola e no ensino. A iniciativa privada pressupõe que a educação pública é ineficiente e, assim, apresenta políticas a serem introduzidas para alcançar resultados aliados aos seus interesses. Nessas políticas, encontramos os pacotes de formação, os materiais a serem seguidos, as avaliações em larga escala, índices a serem alcançados.

Nessa lógica, quem pensa e organiza o trabalho pedagógico na escola não são os sujeitos da escola. Estes não são considerados sujeitos produtores do conhecimento, pois, conforme Santos (1984), aos moldes do capitalismo, apenas alguns produzem e possuem o conhecimento, os quais o transmitem aos outros, neste caso, aos coordenadores pedagógicos.

Outro fator a ser considerado é referente aos gestores das Secretarias de Educação, que, de acordo com Santos (1992), possuem seus sistemas ideológicos restringidos às relações de mercado, de modo a expressar as práticas capitalistas, preocupando-se com a circulação e a distribuição do conhecimento. Eles detêm conhecimentos sobre os processos e, assim, mantêm o domínio sobre a classe trabalhadora. Portanto, são os gestores das Secretarias que organizam o sistema e pensam a formação continuada dos coordenadores pedagógicos de forma a atingir os objetivos esperados por eles.

\section{Considerações finais}

A partir dos dados coletados nesta pesquisa, questionamo-nos: Qual é o espaço que o coordenador pedagógico tem para pensar o seu trabalho na formação continuada ofertada pela Secretaria de Educação? A formação continuada proporciona pensar a prática, questioná-la, buscar fundamentos para negá-la e, assim, pensar, refletir e buscar a transformação?

Afirmamos que a análise seguiu este caminho, levando em conta o referencial que assumimos nesta pesquisa, e as discussões são trazidas nesse viés. Não obstante, as discussões seriam outras se seguíssemos outro caminho. Tivemos a oportunidade de pensar no coordenador 
pedagógico, que está imerso no cotidiano escolar e que necessita de um olhar diferenciado para que realize seu trabalho, reflita e tenha clareza de sua função, a fim de organizar o trabalho pedagógico comprometido com uma escola democrática.

\section{Referências}

ADRIÃO, Theresa Maria de Freitas; PERONI, Vera Maria Vidal. Consequências da atuação do Instituto Ayrton Senna para a gestão da educação pública: observações sobre 10 estudos de caso. Práxis Educativa, Ponta Grossa, v. 6, n. 1, p. 45-53, jan./jun. 2011. DOI: https://doi.org/10.5212/PraxEduc.v.6i1.0004

ALMEIDA, Claudia Maria de; SOARES, Katia Cristina Dambiski. Pedagogo escolar: as funções supervisora e orientadora. Curitiba: Ibpex, 2010.

ANFOPE. Associação Nacional pela Formação dos Profissionais da Educação. Documento Final do IX Encontro Nacional. Campinas: AFOPE, 1998.

BARDIN, Laurence. Análise de conteúdo. São Paulo: Edições 70, 2010.

BRECKENFELD, Eleane Jean Negrão; GUIRAUD, Luciene; ROMANOWSKI, Joana Paulin. Considerações sobre a formação continuada do pedagogo escolar no sistema de ensino público estadual paranaense (2004-2008): possibilidades e limites. In: CONGRESSO NACIONAL DE EDUCAÇÃO, 6., 2009, Curitiba. Anais... Curitiba: PUCPR, 2009. p. 3619-3633.

D'ÁVILA, Jorge Luis. Política de formação docente executada pelo terceiro setor: considerações sobre a Fundação Lemann. In: EDUCERE, 11., 2013. Curitiba. Anais [...]. Curitiba: PUC-PR, 2013. p. 11558-11569.

DOMINGUES, Isaneide. O coordenador pedagógico e o desafio da formação contínua do docente na escola. 2009. 237 f. Tese (Doutorado em Educação) - Faculdade de Educação, Universidade de São Paulo, São Paulo, 2009.

GEGLIO, Paulo Cesar. O papel do coordenador pedagógico na formação do professor em serviço. In: PLACCO, V. M. N. S.; ALMEIDA, L. R. (orgs.). O coordenador pedagógico e o cotidiano da escola. 9. ed. São Paulo: Edições Loyola, 2012. p.113-119.

IMBERNÓN, Francisco. Formação docente e profissional: formar-se para a mudança e a incerteza. 9. ed. São Paulo: Cortez, 2011.

KUENZER, Acacia Zeneida. Trabalho pedagógico: da fragmentação à unitariedade possível. In: AGUIAR, M. A. S.; FERREIRA, N. S. C. (orgs.). Para onde vão a orientação e a supervisão educacional? Campinas: Papirus, 2002. p.47-78.

MARTINS, Pura Lucia Oliver. A relação conteúdo-forma: expressão das contradições da prática pedagógica na escola capitalista. In: VEIGA, I. P. A. (org.). Didática: o ensino e suas relações. Campinas: Papirus, 1996. p. 77-103. 
MARTINS, Pura Lucia Oliver. As formas e práticas de interação entre professores e alunos. In: VEIGA, I. P. A. (org.). Lições de didática. Campinas: Papirus, 2006. p. 75-100.

NÓVOA, António. Formação de professores e profissão docente. In: NÓVOA, A. (org.). Os professores e a sua formação. 2. ed. Lisboa: Publicações Dom Quixote, 1995. p. 15-34.

PERONI, Vera Maria Vidal. As relações entre o público e o privado nas políticas educacionais no contexto da terceira via. Currículo sem Fronteiras, v. 13, n. 2, p. 234-255, maio/ago. 2013.

PINTO, Umberto de Andrade. Pedagogia escolar: coordenação pedagógica e gestão educacional. São Paulo: Cortez, 2011.

PLACCO, Vera Maria Nigro de Souza. O coordenador pedagógico no confronto com o cotidiano da escola. In: PLACCO, V. M. N. S.; ALMEIDA, L. R. (orgs.). O coordenador pedagógico e o cotidiano da escola. 9. ed. São Paulo: Edições Loyola, 2012. p. 47-60.

PLACCO, Vera Maria Nigro de Souza. Formação de professores: o espaço de atuação do coordenador pedagógico-educacional. In: FERREIRA, N. S. C.; AGUIAR, M. A. S. (orgs.). Para onde vão a orientação e a supervisão educacional? Campinas: Papirus: 2002. p. 95-106.

PLACCO, Vera Maria Nigro de Souza; SOUZA, Vera Lucia Trevisan de; ALMEIDA, Laurinda Ramalho de. O coordenador pedagógico: aportes à proposição de políticas públicas. Cadernos de Pesquisa, São Paulo, v. 42, n. 147, p. 754-771, set./dez. 2012. DOI:

http://dx.doi.org/10.1590/S0100-15742012000300006

ROMANOWISKI, Joana Paulin et al. Inserção profissional dos professores da educação básica: dos desafios iniciais às proposições de superação. In: SOUZA, F. D. (org.). Professores principiantes e a inserção à docência: contextos, programas e práticas formativas. Curitiba: Ed. UTFPR, 2016. p. 3455.

SÁNCHEZ GAMBOA, Silvio. A. Pesquisa em educação: métodos e epistemologias. Chapecó: Argos, 2007.

SANTOS, Oder José. A questão da produção e da distribuição do conhecimento. Educação em Revista, Belo Horizonte, n. 2, p. 4-7, dez. 1984.

SANTOS, Oder José. Pedagogia dos conflitos sociais. Campinas: Papirus, 1992.

SAVIANI, Dermeval. A pedagogia no Brasil: história e teoria. Campinas: Autores Associados, 2008.

SAVIANI, Dermeval. Formação de professores: aspectos históricos e teóricos do problema no contexto brasileiro. Revista Brasileira de Educaşão, Rio de Janeiro, v. 14, n. 40, p. 143-155, jan./abr. 2009.

SCHEIBE, Leda; AGUIAR, Marcia Angela. Formação de profissionais da educação no Brasil: o curso de pedagogia em questão. Educação \& Sociedade, Campinas, ano XX, n. 68, p. 220-238, dez. 1999.

VAILLANT, Denise; MARCELO, Carlos. Ensinando a ensinar: as quatro etapas de uma aprendizagem. Curitiba: Ed. UTFPR, 2012. 


\section{Dialogia}

Recebido em: 22 maio 2019 / Aprovado em: 21 nov. 2019

\section{$\underline{\text { Cite como }}$}

CARTAXO, Simone Regina Manosso; GAIO, Victoria Mottim. Coordenador pedagógico: possibilidades e limites da formação continuada. Dialogia, São Paulo, n. 33, p. 115-130, set./dez. 2019. Disponível em: https://doi.org/10.5585/Dialogia.n33.13961. 